\title{
CLARIFYING CHEMISTRY CONCEPTS THROUGH LANGUAGE ANALYSIS
}

\author{
Liliana Mammino \\ Department of Chemistry, University of Venda, Thohoyandou, South Africa, sasdestria@yahoo.com
}

\begin{abstract}
Chemistry concepts often pose considerable challenges to students at all levels of instruction, from secondary school to all the university courses. The search for options to facilitate clear and complete understanding is a major commitment of chemistry education research. Teaching and learning depend on communication effectiveness. Language is the most fundamental communication tool. Its communication effectiveness in education depends on the degree of rigour and clarity with which sentences are built and assembled to form a text, and on the learners' ability to identify all the information conveyed by the text. Language analysis proves a powerful tool to facilitate full identification of the information in a text. It is also optimal to stimulate further reflection on the various features of a concept through the analysis of frequently occurring errors or of errors in learners' work. After an introduction on the reasons making language analysis a powerful clarification tool, this paper considers illustrative examples from different tertiary-level chemistry courses, to highlight the practical implementation aspects and emphasise the integration between the analysis of chemistry concepts and the language-type analysis of the sentences expressing them. Because of its nature, the approach relies on in-class interactions. It has proved beneficial and rich of potentials for further explorations. The design of options for close collaboration between chemistry teachers and language teachers is expected to become the key for more generalised application.
\end{abstract}

Keywords: chemistry teaching, error analysis, interactive teaching, language in chemistry, language and science.

\section{Introduction}

Experience shows that chemistry learning poses substantial challenges at all levels of instruction (from secondary school to university) and for all the aspects - understanding concepts, experimental procedures and problem solving procedures, and being able to relate experimental procedures and observations, or problem solving procedures, to concepts. Learning challenges largely derive from the nature of chemistry as the science of substances, where the understanding of properties and events of the microscopic world of atoms and molecules is the key to understanding the macroscopic behaviours of substances (broader reflections on the relationships between the nature of chemistry and the learning challenges will be incorporated in a separate, philosophy-based work). Students' difficulties with regard to understanding the particulate nature of matter, or relating it to macroscopic descriptions and phenomena, have been the objects of numerous studies in the last decades; a meaningful review would go beyond the size and the scope of the current work; some pioneering works 
like those by Ben-Zvi, Eylon \& Silberstein (1986), Gabel, Samuel \& Hunn (1987) and Gabel (1993) might be recalled as examples of investigation questions and approaches.

The major challenge for educators is the design of options that can help facilitate students' understanding of chemistry. This work focuses on the utilization of language analysis as a tool to provide clarifications and to engage students actively.

A number of studies (e.g., Munby, 1976; Carre, 1981: Muralidhar, 1991; Sutton, 1992; Lahore, 1993; Wellington \& Osborne, 2001; Brooks, 2006; Fang, 2006; Mammino, 2010a, 2010b, 2012a, 2013a; Marshall et al., 2011) indicate the crucial role of language mastery in determining learning success. Teaching and learning depend on teacher- learner communication (including the communication realised through a textbook or other learning resources) and on the learners' ability to develop thoughts. Language is the most fundamental instrument of thought (Bruner, 1975) and, therefore, of cognitive processes (Chomsky, 1975), as well as the most fundamental communication tool. Communication is a two-side enterprise and its effectiveness depends on crucial aspects for each side. The communication effectiveness of language in education depends on the degree of rigour and clarity (Mammino, 2000) with which sentences are built and assembled to form a text (where the term text includes both written and verbally-expressed sentences or sets of sentences) and on the learners' ability to identify all the information conveyed by the text, which, in turn, depends on the learners' language mastery. Therefore, language mastery is a major key for the teaching and learning process and for conceptual understanding.

Learners' (and sometimes teachers') language mastery is not always adequate for the demands of science learning. Challenges in this regard have increased in recent decades because of the fast decline in the language mastery level of the young generations (e.g., Baricco, 2006; Mastrocola, 2011). This decline is determined by a variety of reasons, such as the decrease in written and oral expression-training in pre-university instruction, the decrease in the frequency of books-reading and the habit of building oversimplified skeletal sentences prompted by the dominance of SMS-type communication. The consequences comprise increasing difficulties with:

- reading complex sentences (sentences consisting of more than one clause), and corresponding difficulties with complex reasoning - both of which are essential for science learning;

- expressing acquired knowledge, including the description of systems, phenomena, experiments and observations.

In view of this, attention to language in science teaching becomes increasingly important.

The recognition of the diffuse inadequacies in language mastery has already prompted some interventions, such as initiatives to upgrade learners' language mastery in crucial stages of their learning career, e.g., when first entering university. For instance, since the ability to understand complex sentences and complex discourses plays fundamental roles in science learning, it is necessary to foster it when it is not adequately developed. The recommendations for the Written Italian Service courses meant to upgrade language 
mastery for students entering the University of Venice (Italy) a few years ago specifically stressed the objective that students attain "expression and writing abilities including complex discourses" (A. L. 2009). However, such intervention courses, while apt to set some foundations, are not likely to achieve complete solution of the problem, because language and expression training is a long-term process. Therefore, attention to language continues to be essential within the science courses.

The importance of specific attention to language in science teaching is widely recognised. Sutton (2003) envisages science teachers as language teachers and stresses the pedagogical value of underlining the relationships between science development and language development: "When an area of scientific thought is new, the interpretative role of language is central. New ways of seeing what is going on are closely connected with new ways of talking about it" (Sutton, 2003, pg. 21). Brown \& Ryoo (2008) speak of "teaching science as a language".

Specific attention to language in science teaching may take a variety of implementation pathways. For instance, options focusing on "literacy in its fundamental sense" (Norris \& Phillips, 2003) imply attention to language and expression by involving the key components of literacy, i.e., reading and writing. Their benefits are extensively reported (e.g., Davies \& Greene, 1984; Norris \& Phillips, 2008, for reading and Beall, 1991, 1993, 1994; Cooper, 1993; Beall \& Trimbur, 1993; Wilson 1994; Castro, 1995; Rossi, 1997; Kovac, 1999; Whelan \& Zare, 2003; Ablin, 2008; Mammino, 2013b, for writing within chemistry courses).

This work considers the use of language analysis as an integral component of science teaching. Language analysis is viewed in its fundamental sense: analysis of individual words; analysis of the way in which words relate to each other (e.g., subject and verb; subject, verb and object; noun and adjective); analysis of logical connections between different words in a clause (through prepositions and through words' mutual positions), between different clauses in a sentence (through logical connectives) and between different sentences in a discourse (identifying its logical framework). In other words, the analysis utilises careful attention to the meaning of individual words and to grammar as support to explanations and as a component of in-class interactions.

Language analysis has a variety of pedagogical roles. It is a powerful clarification tool for science concepts, as it:

- facilitates the identification of the information expressed by a text, on introducing a new concept;

- is apt to stimulate deeper reflection on the various features of a concept through the consideration of how it is expressed;

- is suitable for options such as error-analysis integrating conceptual and language perspectives (Love \& Mammino, 1997; Mammino, 2002a);

- is suitable for in-class interactions (actually, it is more effective within interactive approaches). 
Thus, language analysis simultaneously trains students to understand what they read or listen, and to use language appropriately when they wish (or need) to express what they have learnt.

\section{Methodology}

The approach presented here has been developed by the author while working at the University of Venda (UNIVEN, South Africa) in the last 17 years. Like in most cases in SubSaharan Africa, UNIVEN is a second-language instruction context, i.e., the language of instruction (English) is different from the students' mother tongue. This situation is known to pose additional challenges to comprehension and learning, because the mastery of the second language (unavoidably lower than that of the mother tongue) is often inadequate for the needs of science learning (Prah, 1993, 1995, 2002; Benson, 2004; Brock-Utne \& Hopson, 2005; Mammino, 2010a, 2013a; Oven-Smith, 2010; Qorro, 2013). Therefore, specific attention to language becomes an essential tool to make understanding possible. The development of the approach was based on careful investigation of the difficulties experienced by chemistry students, considering both specific language aspects (Mammino, 1998, 2005a, 2006a, 2007, 2009) and specific chemistry issues whose understanding or recognition are particularly affected by language difficulties (Mammino, 2001a, 2001b, 2002b, 2003a, 2003b, 2004, 2006b, 2008, 2011a, 2011b, 2012b, 2012c, 2013c, 2014a).

The development of the approach followed a sort of recursion-type optimization for which any implementation experience is utilised for further improvement to pursue better facilitation of understanding. The development was made possible by the fact that the author's education comprised extensive humanities background, which enables quick recognition of language-related difficulties and the expertise to deal with them. The approach has been applied within the courses taught by the author, comprising the first year general chemistry course, the second year, third year and first postgraduate year physical chemistry courses and the third year process technology course.

The approach is not codified, but flexible, because it aims at responding in real-time to the specific diverse problems that surface during in-class work. The implementation relies on the recognition of language-related difficulties as soon as they appear and on quick responses to each of them. The options that have proved more effective for language analysis will be described in the next paragraphs and sections (by "more effective" is meant that the options result in the understanding of something that was not clear before the language analysis was performed).

Depending on the focus of attention at a given moment, language analysis may be performed mostly by the teacher or in an interactive way. When the material presented in a lecture comprises complex sentences that need to be understood in a given formulation (such as some definitions or the statements of some laws), it is mostly performed by the teacher, although interactions are utilised whenever possible. More often, it is carried out in terms of error analysis, to highlight how errors in the expression often imply conceptual chemistry 
errors. Then, the analysis is performed interactively. The sentence or statement to be analysed is written on the board. The teacher utilises questions to step-wise guide students to reach conclusions (Mammino, 2006c). The questions need to be suitable for each specific case, to stimulate reflection on its relevant features. They are asked verbally to the whole class, and students are invited to answer verbally. In many cases, the first question focuses on the literal meaning of the incorrect statement. Besides being important as a starting point, this also contributes to partially address one of the major identified problems - the fact that students usually do not proofread or verify the meaning actually conveyed by the statements that they write, because they are unaware that careful proofreading could prevent many mistakes or because they do not have the skills to do it efficiently. Each question remains open until at least one student finds the correct answer. In this way, the exercise is a cooperative search for the correct chemistry meaning and for the correct way to express it. The errors proposed for analysis are selected among those that appear more frequently in students' works, to address concrete problems experienced by many students. Errors that might appear in learning materials are always analysed. Visualisation is also utilised whenever possible, as it reinforces the messages and facilitates clarification (Mammino, 2014b).

\section{Examples of the use of language analysis in chemistry teaching}

This section presents selected examples to illustrate how the analysis is performed in practice. To increase readability, different aspects of language analysis are grouped under different subsections. Most examples refer to error analysis because of their greater suitability for in-class interactions. The examples are presented in a schematic form (bulleted format) to better highlight the relevant components, although it is impossible to reproduce the richness of verbal interactions. The main components are the following:

- The set of questions utilised to guide students through the analysis. Each question is here identified by a Q. A working context often involves more questions than those reported in the examples.

- The corresponding correct answers, here identified by A and included to facilitate readability. The answers indicated can be generic: for instance, the third $A$ in example 4 says that "any monoatomic ion provides a suitable answer", but students will usually provide concrete examples $\left(\mathrm{Na}^{+}, \mathrm{Cl}^{-}\right.$, etc). When suitable, the $A$ may also contain hint to clarifications that are stressed by the teacher. When the answer is only a self-evident yes or no, it is not reported.

- Reference to the reinforcing visualisation options that can be utilised, when suitable. Each example is preceded by a short comment introducing its main significance. It is important to note that the examples as they are reported here illustrate possibilities: the guiding questions are not rigid (are not always the same, even for the same type of error), because their formulation depends on how interactions develop in a given moment and, 
therefore, on students' responses. And the answers are not rigid, because different students formulate them differently.

\subsection{Accurate Selection of Individual Words}

Communication in science depends on the words linking the technical terms to build a meaning. These are the common words (verbs, adjectives, prepositions, logical connectives, etc.) pertaining to the language utilized. In any scientific discourse, technical terms (the terms denoting the objects or phenomena of interest in a given science) are immersed in a sea of common words (Mammino, 2006d) which constitute the backbone of the communication. For instance, in the sentence

Bohr made the hypothesis that the angular momentum of the electron in the atom is quantized

the backbone of the sentence, realising the information, are the words Bohr (subject), made (verb), the hypothesis (object), that (logical connective between clauses), of the (expression of a specification), in the (expression of place) and is (verb of the subordinate clause). The technical terms (underlined in the sentence above) are essential, as they are the names of the items about which one is talking, but the expression of the information depends on the common words connecting them. Therefore, the way in which common-language words are used is an optimal object of analysis, because it is tantamount to analyse the details of the information conveyed by a sentence.

Example 1. The selection of the subject is a key issue for any clause. When the selection is not correct, the scientific meaning is lost.

- Sentence to be analysed: ideal gases move in a straight line.

- Convenient steps of the analysis:

$\circ$ Q. What are we talking about? This implies identifying what is moving in a straight line.

$\circ$ Q. What is the correct subject?

- The molecules of ideal gases.

Q Q. What is the main conceptual issue in question?

- The difference between microscopic and macroscopic descriptions in chemistry.

- Visualization: students are invited to draw representations of the meanings conveyed by the two sentences - the incorrect one and the one with a correct subject. The visualization of the meaning of the incorrect sentence unavoidably prompts amusement, as they realize the discrepancies between what they wanted to say and what they actually said.

Example 2. The correct matching of subject and verb is fundamental for a sentence to convey a meaning.

- Sentence to be analysed: The equations for real gases consist of the parameters which depend on the chemical nature of gas. 
- Convenient steps of the analysis:

$\circ$ Q. What is the meaning of the verb consist?

A. It is used when we want to specify what something is made of, considering all its components.

- Q. Take one of the state equations of real gases as an example, e.g., the van der Waals state equation. Identify the parameters. Does the equation consist only of those parameters or are there other terms?

A. There are other terms (the state variables). (The parameters in the van der Waals state equation are $a$ and $b$ ).

- Q. Identify the correct verb.

A. contains, which does not imply that we are listing all the components.

Example 3. It is always necessary to clearly specify what we are talking about.

- Sentence to be analysed: The electrode in which it is reduced is called cathode.

- Convenient steps of the analysis:

$\circ$ Q. What is reduced? Can we identify it from the sentence?

$\circ$ Q. What happens at the cathode of an electrochemical cell?

A. A species is reduced.

$\circ$ Q. How can we express it correctly?

A. Possible options are "the electrode at which reduction occurs...", "the electrode at which a species is reduced...", or similar ones.

$\circ$ Q. What is the main language issue in question?

A. The importance to specify what we are talking about. This also implies not using undefined pronouns (it, they, and the corresponding adjectives its, their) unless they can be easily related to a previously-appearing noun.

Example 4. Each individual term conveys a specific meaning and it is important to understand it. When considering a definition, it is important to underline the role of each key term, above all when experience has shown that students may tend to overlook the term and its significance.

- Sentence to be analysed: the definition of oxidation number: The oxidation number is a formal charge ascribed to elements on the basis of the conventional criterion that, for each bond, all the electrons are ascribed to the more electronegative element.

The operational meaning of the definition is analysed with the help of visualization (Mammino, 2014b). But some individual words require additional emphasis for the concept to be clearly understood. A key word is the adjective formal.

- Convenient steps of the analysis.

$\circ$ Q. Why do we speak of formal charge?

A. Because, in most cases, the charge is not real.

$\circ$ Q. What is the specific role of the adjective formal? 
A. To inform us that, in most cases, the charge is not real (it is part of our descriptions, a convenient tool in our description of redox reactions).

$\circ$ Q. Can you give an example where the charge is not formal, but real?

A. Any monoatomic ion provides a suitable answer.

- Q. Can you give an example where the charge is only formal?

A. The elements in any molecule offer suitable answers.

\subsection{Connections of Words in a Clause}

The way in which words are connected to build a clause needs to respond to the grammar rules of the language utilised and to conceptual logic, so that the clause can convey identifiable and correct information. The analysis considers all these aspects: grammarbased aspects such as the use of prepositions, the expression of comparisons, etc.; and aspects related to the logic of the expression, including the roles of words in the given context and the presence of all the words that are essential to convey the wanted information.

Example 5. A sentence may fail to convey information because not all its components are expressed correctly.

- Sentence to be analysed: First order reaction does not depend on the initial concentration.

- Convenient steps of the analysis:

$\circ$ Q. What is the literal meaning of this sentence?

A. It tells us that a phenomenon (a first order chemical reaction) does not depend on the initial concentration.

$\circ$ Q. What are the problems with this statement?

A. It should specify a physical quantity (not a phenomenon) as subject of "does not depend on the initial concentration". Moreover, it does not specify which concentration we are considering.

$\circ$ Q. Does the statement (as it is) relate to anything that we have learnt?

$\circ$ Q. Which property of a first order reaction does not depend on the initial concentration?

A. The half-life of the reactant.

$\circ$ Q. Which concentration are we considering? (concentration of what?).

A. The concentration of the reactant.

$\circ$ Q. Build a correct sentence.

A. In a first order reaction, the half-life of the reactant does not depend on its initial concentration.

Example 6. Definitions of chemical equilibrium provided by students often show misconceptions, such as considering that all the concentrations must be equal (Tyson et al., 1999). In some cases, the provided definitions imply meanings that do not correspond to actual misconceptions (to what students actually think), but to lack of awareness of the meaning actually conveyed by the sentence. 
- Sentence to be analysed: at equilibrium all the species must be the same.

- Convenient steps of the analysis:

$\circ$ Q. What is the literal meaning of this sentence?

A. It tells us the all the species are the same.

- Q. In a situation in which "all the species are the same", how many species are present?

A. Only one.

- Q. Is this compatible with the chemical reaction concept?

A. No, because a reaction mixture needs to contain at least two different species (one reactant and one product).

- Q. What quantity should not change for a reaction at equilibrium?

A. The concentrations of all the species present (it usually takes some time for students to identify this answer).

○ Q. Build a correct sentence.

A. A chemical reaction is at equilibrium if the concentrations of all the species present in the reaction mixture do not change over a sufficiently long time.

Example 7. Prepositions define the role of the other components of a clause (besides the subject and the verb) and, thus, they play key roles in identifying what we are talking about.

- Sentence to be analysed: bonds in ice molecules are stronger than bonds in liquid water.

- Convenient steps of the analysis:

- Q. Which bonds are we considering if we speak of the bonds in a molecule?

A. The bonds between the atoms that form that molecule.

$\circ$ Q. Are these the bonds that we consider when we compare different phases of the same substance?

Q. Which bonds should we consider in this case?

A. The bonds between different molecules.

- Q. Are the molecules in ice different from the molecules in liquid water?

A. No, because a phase transition does not imply a change in substance.

- Q. Build a correct sentence.

A. The bonds between water molecules are stronger in the solid than in the liquid.

- Visualization: two (or more) water molecules in the correct arrangement to form hydrogen bonds are drawn on the board, and students are invited to identify the bonds in the molecules and the bonds between the molecules; the meaning of the terms intramolecular and intermolecular is correspondingly stressed.

Example 8. In sentences with more than one clause, if the information in each clause is not complete, the entire sentence may fail to have a meaning.

- Sentence to be analysed: when two elements with different tendencies come into contact, high tendency will give out electrons than the other. 
- Convenient steps of the analysis:

○ Q. The word tendency has a broad meaning and remains undefined if we do not specify its nature. Which tendency are we considering in this case?

A. The tendency to be in an oxidised state.

○ Q. This tendency is a property (a quality, or a physical quantity) of elements. Can a quality or a physical quantity give out electrons?

$\circ$ Q. What entity can give out electrons?

A. An atom.

○. What is the literal meaning of the principal clause as expressed here (high tendency will give out electrons than the other)?

A. It tells us that one element releases electrons to a greater extent than the other.

- Q. Does this make sense in the situation considered here (two elements with different tendencies to be in an oxidised state coming into contact)? Why?

A. When only two elements are present, they cannot both release electrons. If one element releases electrons, there must be another element accepting those electrons. So, the comparison implied by the preposition than has no meaning.

- Q. Build a correct sentence.

A. When two elements with different tendencies to be in an oxidised state come into contact, the element with higher tendency will give electrons to the element with lower tendency.

\subsection{Connections of Clauses in a Sentence}

The connections of clauses in a sentence respond to logical relationships such as cause-effect, time sequences, hypothesis-inference, condition-consequence, etc. The conjunctions connecting clauses and expressing these relationships are often called logical connectives. In the case of complex sentences, error analysis considers the actual meaning of the statement used as example, its correspondence with the conceptual meaning, the logical relationships relevant to the given case and the way in which they are to be expressed.

Example 9. Cause-effect relationships appear particularly challenging for students, likely because their identification involves simultaneous familiarity with the concepts (chemistry content) and with logic (Mammino, 2006b). Answers stating cause-effect relationships between aspects for which the relationship does not exist are frequent. The analysis aims at identifying why the expressed relationship is not correct and - when possible - at identifying correct relationships. In most cases, however, it is not possible to ask students to build a correct statement, because the incorrect statement relates things that cannot be related.

- Sentence to be analysed (a sentence in a report on an experiment requiring qualitative observations of what happens when a piece of a certain metal is dipped in a solution 
containing ions of another metal): In test 5, tin has a larger concentration since an electrolytic solution conducts electricity because of the movement of ions in the solution.

- Convenient steps of the analysis:

$\circ$ Q. Did we measure conductivity or concentration in the experiment? The question is important to stimulate students to reflect on how a report must focus on what was actually done in the experiment and what can be inferred from it. In the given case, since the experiment was qualitative, it did not involve measurements of conductivity or concentration.

$\circ$ Q. What is the meaning conveyed by this statement, literally?

○ Q. Can the fact that electrolytic solutions conduct electricity be the cause of whether the concentration of a certain sample is higher or lower than that of another sample?

A. There is no cause-effect relationship between the fact that electrolytic solutions conduct electricity (a general phenomenon) and the value of the concentration of a given solution.

- Q. What could be the terms of a correct relationship between the ability of electrolytic solutions to conduct electricity and their concentrations?

A. Relating the conductivity to the concentration of ions (the higher the concentration of ions in a solution, the higher its conductivity).

Example 10. The correct identification of cause-effect relationships is fundamental for the interpretation of experimental information.

- Sentence to be analysed (from a lab report on an experiment on electrolysis): The phenomena observed in this experiment on electrolysis are non-spontaneous because electrolysis is a process in which a non-spontaneous redox reaction is forced to occur by electric current.

- Convenient steps of the analysis:

$\circ$ Q. Does the second clause (introduced by because) actually provide the reason (cause) why the phenomena observed are non-spontaneous?

$\circ$ Q. When we discuss an experiment, the reasons for our inferences must be in terms of experimental observations. Does the statement comply with this?

○ Q. Which observations show the non-spontaneity of the phenomena observed?

A. The fact that we needed to use electric current for them to occur.

- Q. Build a correct statement.

A. A possible correct statement is "The phenomena observed in this experiment on electrolysis are non-spontaneous because they needed the use of electric current to occur".

\subsection{The Logic of a Discourse}

The logic of a discourse (a text consisting of more than one sentence) depends on the correct sequence and connections among the different pieces of information forming it. On 
explanation, the logic can be highlighted through the analysis of the meaning of each sentence, and of how sentences relate to each other, identifying the different pieces of information and their connections. In some cases, the use of flow-charts proves useful. The analysis of errors in a discourse considers its actual meaning with reference to the given theme, the logic faults responsible for conveying an incorrect meaning, and the correct way of conveying the wanted meaning.

Example 11. Models are an essential component of the scientific approach. Understanding and comparing models requires mastery of conceptual aspects such as the meaning of hypothesis, and of language aspects such as the expression of what is real and what is not (e.g., what actually happened and what could have happened but did not happen (Mammino, 2005b).

- Discourse to be analysed: In Thomson model all the a particles behave in the same way. In Rutherford's model they behave in different ways.

- Convenient steps of the analysis:

$\circ$ Q. How do we investigate the behaviour of something?

A. Experimentally.

$\circ$ Q. Do we investigate the behaviour of something through a model?

A. No. A model is built after experimental observations have shown some patterns. It enables us to make predictions, which must in turn be verified through experiments.

$\circ$ Q. How did the a particles behave in Rutherford experiment?

A. They behaved in different ways.

- Q. Does the discourse above make this clear?

A. No. It states what the model predicted, not what happened in the experiment.

○ Q. Consider the whole statement. Does it enable us to know what really happened?

A. No. It depicts a scenario where $\alpha$ particles can behave both in the same way and in different ways.

- Q. How does grammar enable us to distinguish between what actually happened in the experiment and what should have happened if Thomson model were the one corresponding to reality, but did not happen?

A. This requires recalling the function of the logical connective if and the conjunctive mode of verbs.

- Q. Build a correct statement.

A. In Rutherford experiment, the a particles behaved in different ways. If Thomson model had been true, the a particles should have behaved in the same way. 


\section{Results}

The results of designing and implementing an approach are seen through everyday classroom experience, from students' responses. The relevant responses may be different for different approaches. The approach outlined in this work is a dynamic one meant for interactions and, therefore, the relevant responses include the level of participation in classroom interactions, the attainment of understanding after a given the exercise is completed and the attitude towards new exercises of the same type when new difficulties are encountered.

The major result is that the approach always leads to the understanding of the concept considered. Students' attitude changes as the course proceeds and they experience the benefits of the approach: their participation in the interactions increases and they increasingly recognise the exercises as an important tool to understand the material. From the teacher's perspective, these responses constitute a validation of the approach. At the same time, the details of each exercise (how fast students answer, what they answer and what they ask) constitute valuable information for further improvement.

\section{Discussion and Conclusions}

Experience shows that the approach outlined in this work always leads to understanding. However, its utilisation is limited by time constraints: it can be applied to key issues or recurrent errors, but it is not realistic to apply it to each and every sentence utilised in class or present in books, although this would be extremely important for students whose language mastery is inadequate.

The approach requires students' active engagement to be effective, thus requiring extensive in-class interaction. Questions are viewed as the best way to stimulate students' attention and to guide reflections through a collaborative search meant to analyse sentences or texts, discuss the associated chemistry concepts and build correct statements after the concepts are completely clear. The guiding questions for each case depend on the statement that is the object of the analysis and on students' responses during interactions. Therefore, the teacher needs to be able to provide immediate response to any new statement or question from the students, to ensure effective guidance.

The key feature of the approach is the integration between the analysis of chemistry concepts and the language-centred analysis of the sentences expressing them. The examples in section 3 provide basic illustration of how the integration can be realised. However, the language-centred component of the analysis may pose some challenges to chemistry teachers who did not receive extensive humanities education. Therefore, the search for innovative options for collaboration between chemistry teachers and language teachers in the same class may play key roles.

Although some of the errors in the examples considered in section 3 are encountered more frequently in second language contexts (like UNIVEN), similar errors start appearing also in mother-tongue instruction contexts, as the level of language mastery decreases (Mastrocola, 2011). By utilising language analysis as an explanation and reflection tool to clarify chemistry 
concepts and favour their internalisation, the approach has potentialities for all contexts. For instance, exercises based on typical language aspects were included in an Italian chemistry textbook (Mammino, 2003c) to stimulate reflection on the chemistry concepts and were encountered positively by teachers. 


\section{CLARIFYING CHEMISTRY CONCEPTS \\ THOUGH LANGUAGE ANALYSIS}

\section{References}

Ablin, L. (2008). Student perception of the benefits of a learner-based writing assignment in organic chemistry. Journal of Chemical Education, 85 (2), 237-239.

A. L. (2009). E anche le tesi di laurea sono incomprensibili. Il Tirreno, 12 December 2009, page 25.

Baricco, A. (2006). I Barbari. Saggio sulla mutazione. Rome: Fandango.

Beall, H. (1991). In-class writing in general chemistry: A tool for increasing comprehension and communication. Journal of Chemical Education, 68 (1), 148-149.

Beall, H. (1993). Literature reading and out-of-class essay writing in general chemistry. Journal of Chemical Education, 70 (1), 10-11.

Beall, H. (1994). Probing student misconceptions in thermodynamics with in-class writing. Journal of Chemical Education, 71 (12), 1056-1057.

Beall, H. \& Trimbur, J. (1993). Writing as a tool for teaching chemistry. Report on the WPI conference. Journal of Chemical Education, 70 (1), 478-479.

Benson, C. (2004). The importance of mother tongue based schooling for educational quality. 2005/ED/EFA/MRT/PI/9.

Ben-Zvi, R., Eylon, B. \& Silberstein, J. (1986). Is an atom of copper malleable? Journal of Chemical Education 63(1), 64-66.

Brock-Utne, B. \& Hopson, R.K. (Eds.), (2005). Languages of Instruction for African Emancipation Focus on Postcolonial Contexts and Consideration. Cape Town: CASAS.

Brock-Utne, B. \& Skattum I. (2009). Languages and Education in Africa: A Comparative and Transdisciplinary Analysis. Oxford: Symposium Books.

Brown, B.A. \& Ryoo, K. (2008). Teaching science as a language: A 'content-first' approach to science teaching. Journal of Research in Science Teaching, 45 (5), 529-553.

Brooks, D.T. (2006). The role of language in learning physics. PhD dissertation, State University of New Jersey, USA.

Bruner J. (1975). Language as an instrument of thought. In A. Davies (Ed.), Problems of Language and Learning. Edinburg: Edinburg University Press.

Carré, C. (1981). Language teaching and learning: Science. London: Ward Lock.

Chomsky, N. (1975). Reflections on Language. Included in N. Chomsky, On Language. New York: The New Press, 2007.

Castro, E.A. (1995). Escribir sobre química para aprender química. Panamerican Newsletters, 8 (4), 8-9.

Cooper, M.M. (1993). Writing - an approach for large enrolment chemistry courses. Journal of Chemical Education, 70 (6), 476-477.

Davies, F. \& Greene, T. (1984). Reading for learning in the sciences. Edinburgh: Oliver and Boyd.

Fang, Z. (2006). The language demands of science reading in middle school. International Journal of Science Education, 28 (5), 491-520.

Gabel, D.L., Samuel, K.V. \& Hunn, D. (1987). Understanding the particulate nature of matter. Journal of Chemical Education 64(8), 695-697.

Gabel, D.L. (1993). Use of the particle nature of matter in developing conceptual understanding. Journal of Chemical Education 7O(3), 193-194.

Kovac, S. (1999). Writing in chemistry: An important learning tool. Journal of Chemical Education, 76 (10), 1399-1402.

Lahore A.A. (1993). Lenguaje literal y conotado en la enseñanza de las ciencias. Enseñanza de las Ciencias, $11(1)$, 59-62.

Love A. \& Mammino L. (1997). Using the analysis of errors to improve students' expression in the sciences. Zimbabwe Journal of Educational Research, 9 (1), 1-17. 
Mammino, L. (1998). Science students and the language problem: Suggestions for a systematic approach. Zimbabwe Journal of Educational Research, 10 (3), 189-209.

Mammino L. (2000). Rigour as a pedagogical tool. In S. Seepe and D. Dowling (Eds), The Language of Science, Johannesburg: Vyvlia Publishers, p. 52-71.

Mammino, L. (2001a). Physical quantities and their changes. Difficulties and perceptions by chemistry students. SAARMSTE Journal, 5, 29-40.

Mammino, L. (2001b). General y particular en química. Anuario Latinoamericano de Educación Química, XIV, 25-28.

Mammino L. (2002a) Empleo del análisis de errores para aclarar conceptos de química general, Enseñanza de las Ciencias, 20 (1), 167-173.

Mammino, L. (2002b). La percepción de la distinción entre sistemas y procesos por parte de los alumnos de química. Anuario Latinoamericano de Educación Química, XV, 125-129.

Mammino, L. (2003a). La comprensión de la hibridación de los orbitals atómicos entre aspectos conceptuales y aspectos de lenguaje. Anuario Latinoamericano de Educación Química, XVI, 251-256.

Mammino, L. (2003b). Actitud hacia números y valores en cursos de química general. Anuario Latinoamericano de Educación Química, XVI, 5-10.

Mammino, L. (2003c). Chimica Aperta. Florence: D’Anna.

Mammino L. (2004). Dominancia del concepto de reacción, y de los términos asociados, en la percepciones de alumnos de química. Anuario Latinoamericano de Educación Química XVIII, 46-52.

Mammino, L. (2005a). Language-related difficulties in science learning. I. Motivations and approaches for a systematic study. Journal of Educational Studies, 4 (1), 36-41.

Mammino L. (2005b). Method-related aspects in an introductory theoretical chemistry course. Journal of Molecular Structure (Theochem) 729, 39-45.

Mammino, L. (2006a). Language-related difficulties in science learning. II. The sound concept correspondence in a second language. Journal of Educational Studies, 5 (2), 189-213.

Mammino, L. (2006b). Cause and effect - a relationship whose nature involves conceptual understanding, scientific method, logic and language. Anuario Latinoamericano de Educación Química, XXI, 33-37.

Mammino L. (2006c). The use of questions in the chemistry classroom: an interaction instrument with maieutic nature. Anuario Latinoamericano de Educación Química, XXI, 241-245.

Mammino L. (2006d). Terminology in Science and Technology - an overview through history and options. Thohoyandou: Ditlou.

Mammino, L. (2007). Language-related difficulties in science learning. III. Selection and combination of individual words. Journal of Educational Studies, 6 (2), 199-214.

Mammino L. (2008). Chemistry students' perceptions of the factors influencing phase transitions of pure substances, as expressed in laboratory reports. Anuario Latinoamericano de Educación Química XXIII, 96-100.

Mammino, L. (2009). Language-related difficulties in science learning. IV. The use of prepositions and the expression of related functions. Journal of Educational Studies, 8 (4), 142-157.

Mammino, L. (2010). The mother tongue as a fundamental key to the mastering of chemistry language. In C. Flener \& P. Kelter (Eds.), Chemistry as a Second Language: Chemical Education in a Globalized Society. Washington: American Chemical Society, p. 7-42.

Mammino, L. (2010b). The essential role of language mastering in science and technology education. International Journal of Education and Information Technologies 3 (4), 139-148.

Mammino, L. (2011a). The relative tendencies of elements to be in an oxidised state. I. students' understanding of the background concepts. Anuario Latinoamericano de Educación Química, XXVI, 59-64. 


\section{CLARIFYING CHEMISTRY CONCEPTS \\ THOUGH LANGUAGE ANALYSIS}

Mammino, L. (2011b). The relative tendencies of elements to be in an oxidised state. II. Students' attitudes toward qualitative experimental information. Anuario Latinoamericano de Educación Química, XXVI, 104-109.

Mammino, L. (2012a). Focused language training as a major key for bridging the gap between secondary and tertiary instruction. In D. Mogari, A. Mji \& U.I. Ogbonnaya (Eds.) ISTE International Conference Proceedings "Towards effective teaching and meaningful learning in Mathematics, Science and Technology", p. 278-290.

Mammino L. (2012b). The spontaneity concept: an investigation of the dichotomy between learning the definition and handling the concept. Anuario Latinoamericano de Educación Química XXVII, 120-125.

Mammino L. (2012c). An investigation of students' difficulties in handling the spontaneity concept in electrochemistry. Anuario Latinoamericano de Educación Química XXVII, 155-160.

Mammino L. (2013a). Importance of language mastery and mother tongue instruction in chemistry learning. In Z. Desai, M. Qorro \& B. Brock-Utne (Eds), The Role of Language in Teaching and Learning Science and Mathematics. Somerset West: African Minds, p. 33-56.

Mammino L. (2013b). Teacher-students interactions: The roles of in-class written questions. In MeiHung Chiu (Ed.), Chemistry Education and Sustainability in the Global Age, Dordrecht: Springer, p. 35-48.

Mammino L. (2013c). The Hess law - chemical information from a rigorous statement and challenges experienced by students. Anuario Latinoamericano de Educación Química XXVIII, 167-172.

Mammino L. (2014a). The Hess law and the state-function nature of enthalpy. The concept and its expression by chemistry students. Anuario Latinoamericano de Educación Química XXIX, 100-105.

Mammino L. (2014b). The interplay between language and visualization: the role of the teacher. In B. Eilam \& J.K. Gilbert (Eds.), Science Teachers'Use of Visual Representations, Dordrecht: Springer, p. 195-225.

Marshall, D., Conana, H., Maclons, R., Mark. H., \& Volkwyn, T. (2011). Learning as accessing a disciplinary discourse: Integrating academic literacy into introductory physics through collaborative partnership. Across the Disciplines, 8 (3). Retrieved from httt://wac.colostate.edu/atd/dil/marshalletal.cfm

Mastrocola, P. (2011). Togliamo il disturbo. Saggio sulla libertà di non studiare. Parma: Guanda.

Munby, A.H. (1976). Some implications of language in science education. Science Education, 60 (1), $115^{-124 .}$

Muralidhar, S. (1991). The role of language in science education: Some reflections from Fiji. Research in Science Education, 21, 253-262.

Norris, S.P., \& Phillips, L.M. (2003). How literacy in its fundamental sense is central to scientific literacy. Science Education, 87, 224-240

Norris, S.P., and Phillips, L.M. (2008). Reading as inquiry. In R.A. Duschl \& R.E. Grandy (Eds.), Teaching Scientific Inquiry: Recommendations for Research and Implementation. Rotterdam: Sense, p. 233-262.

Owen-Smith, M. 2010. The language challenge in the classroom. Focus, Journal of the Helen Suzman Foundation, 56, 31-37.

Prah K.K. (1993). Mother Tongue for Scientific and Technological Development in Africa. Bonn: German Foundation for International Development. Education, Science and Documentation Centre.

Prah K.K. (1995). African languages for the Mass Education of Africans. Bonn: German Foundation for International Development. Education, Science and Documentation Centre.

Prah K.K. (2002). The Rehabilitation of African Languages. In K.K. Prah (Ed.), Rehabilitating African Languages. Cape Town: CASAS. 
Qorro, M. (2013). Language planning and policy in Tanzania: When practice does not make perfect. In Z. Desai, M. Qorro \& B. Brock-Utne (Eds), The Role of Language in Teaching and Learning Science and Mathematics. Somerset West: African Minds, p. 151-170.

Rossi, F.M. (1997). Writing in an advanced undergraduate chemistry course: An assignment exploring the development of scientific ideas. Journal of Chemical Education, 74 (4), 395-396.

Sutton, C.R. (1992). Words, Science and Learning. Buckingham: Open University Press.

Sutton, C. (2003). Los profesores de ciencias como profesores de lenguaje. Enseñanza de las Ciencias, 21 (1), 21-25.

Tyson, L., Treagust, D.F. \& Bucat, R.B. (1999). The complexity of teaching and learning chemical equilibrium. Journal of Chemical Education, 76 (4), 554-558.

Wellington, J. \& Osborne, J. (2001). Language and literacy in science education. Buckingham \& Philadelphia: Open University Press.

Whelan, R.J., \& Zare, R.N. (2003). Teaching effective communication in a writing-intensive analytical chemistry course. Journal of Chemical Education, 80 (8), 904-905.

Wilson, J.W. (1994). Writing to learn in an organic chemistry course. Journal of Chemical Education, 71 (12), 1019-1022. 